\title{
Binding of the glucocorticoid and estrogen receptors to the human H-ras oncogene sequences
}

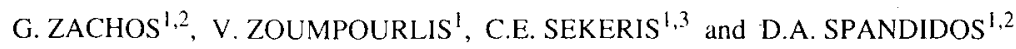 \\ 'Institute of Biological Research and Biotechnology, National Hellenic Research Foundation, Athens; \\ ${ }^{2}$ Medical School, University of Crete, Heraklion; ${ }^{3}$ Medical School, University of Athens, Athens, Greece \\ Contributed by C.E. Sekeris, January 25, 1995
}

\begin{abstract}
There is evidence that hormone regulation of cellular oncogenes plays an essential role in human cancer. The c-H-ras gene is implicated through both mutation and abnormal gene expression in many types of human cancer. Computer scanning of this gene has revealed two putative hormone response motifs: A possible Glucocorticoid Response Element (GRE) at position 1261 of the first intron of the H-rasl gene and a putative Estrogen Response Element (ERE), at position 3007 of the fourth intron of the gene. In DNA binding assays, using the HeLa and LATKcell lines, we showed specific binding of the corresponding receptors at both putative $\mathrm{H}$-ras glucocorticoid and estrogen response sequences, suggesting that hormones could be contributing to H-ras transcriptional regulation through interaction with their corresponding Hormone Response Elements (HREs).
\end{abstract}

\section{Introduction}

Nuclear receptors, such as those for steroid/thyroid hormones, vitamin D, and retinoic acid, are known to act as gene regulators, controlling the transcription of target genes by binding to cis-acting DNA elements referred to as hormone responsive elements (HREs) (reviewed in ref. 1). Negative HREs, which repress expression of specific genes, have been characterized $(2,3)$, however, the mechanism of their action is still poorly understood. Consensus steroid hormone REs correspond to palindromic sequences $(4,5)$, however, either imperfect palindromic HREs $(6,7)$ or their interference with other cis-acting regulatory elements $(8,9)$ or factors (10), may also generate efficient HREs.

Glucocorticoids regulate transcription of a number of genes by the direct interaction of the hormone receptor complex with GREs. GREs contain an imperfect palindromic consensus sequence 5'-GGTACANNNTGTTCT-3', (1) with highly conserved TGTTCT oligonucleotide and quite

Correspondence to: Professor D.A. Spandidos, Institute of Biological Research and Biotechnology, National Hellenic Research Foundation. Vas. Constantinou Avenue, Athens 11635. Greece

Key words: glucoconticoid. estrogen, receptor, $\mathrm{H}$-ras oncogene variable upstream hexanucleotide $(11,12)$. Interference between the glucocorticoid receptor and other transcription factors has also been shown $(13,14)$. The hormone response elements in the conserved 5'-AGGTCANNNTGACCT-3' sequence is the ERE consensus oligonucleotide (5). Additionally, 5'-TGACCT-3' half palindromic oligonucleotides may act synergistically conferring estrogen response to a gene, even at a long distance from the gene promoter $(15,16)$, possibly through estrogen receptorassociated proteins (17). GREs and EREs have been identified and characterized in a number of cellular genes (18-21), as well as in viral regulatory regions (22-25), but little is known about the presense of glucocorticoid and estrogen response elements in cellular oncogenes.

The H-ras gene, a member of the ras family of protooncogenes, is readily implicated in many types of human cancer both through mutation (26) and abnormal gene expression and is involved in multiple signal transduction pathways, under normal cellular growth as well (27). The fact that overexpression of ras genes may cause oncogenic transformation $(28,29)$ and that expression of the normal H-ras gene can act as an onco-supressor (30), indicate the importance of understanding the way ras genes are regulated. Elevated expression of the ras genes has also been found in a variety of human tumors (for a review see ref. 31 ).

Considering the possible role of hormonal steroids as tumor promoters (32), we computer scanned the human c-Hrasl sequence for potential hormone response elements. We observed a putative GRE motif with $100 \%$ similarity in the half palindrome consensus oligonucleotide at position 1261 (GGCCAGACCTGTTCT) of the conserved 3' end of the first intron (33) and a possible ERE motif, with $90 \%$ similarity, at position 3007 (GGGCCACCCTGACCT) of the fourth intron of the H-ras gene. Using gel retardation experiments with nuclear extracts from HeLa and LATK- cell lines, which possess hormone receptors, we showed that both glucocorticoid and estrogen receptors bind their cognate oligonucleotides of H-ras in a specific way, thus suggesting a role for glucocorticoids and estrogens in regulation of the H-ras gene expression.

Materials and methods

Cells and culture conditions. Human cervical epithelial tumor cells (HeLa) and tumor mouse fibroblasts (LATK·) 
are grow

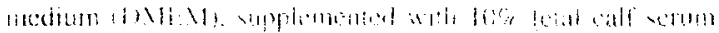

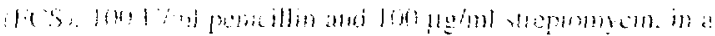

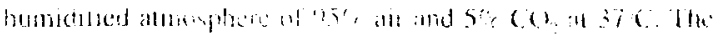

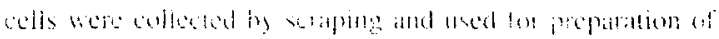
anchere extats

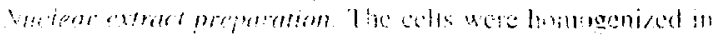

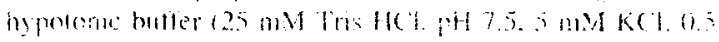

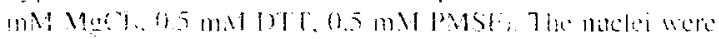

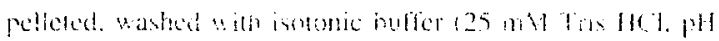

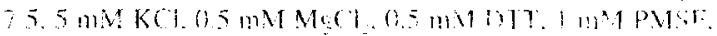

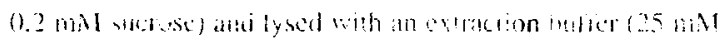

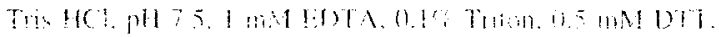

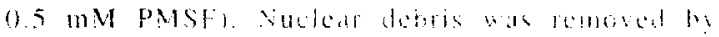

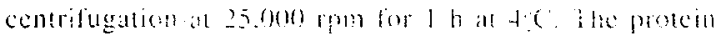
eoneentration of the supunatant was meanteded by the method of Brabliogd.

Prepuration of double stranded oligonmelenites end abelling. Wie PAS GRE probe was obtained by annealing the following two oligonucleotides: 5'-AGCTTCOGCCOCG GCCAGACCIGTTCTGGAGGACA 3; 5' ACBCTTGTCC TCCAGAACAGGTCTGGCCACGGCGGAA-3'. The RAS ERE probe was generated by the olignnucleotides: $5^{\circ}$ AGCITGGGCCCCGGGCCACCCTGACCTTTGAGGGGA-3; 5'-AGCT TCCCCTCAAAGGTCAGGGTGGCC CCGGGC CCA-3'. RAS GRE and RAS ERE probes contain the corresponding hormone response elements of the H-ras gene. The hMTIIA GRE probe, which contans the GRE of the human metallothionein IIA gene promoter (18), was generated hy the oligonucleotides: 5 -AGCTTGGlACACTGTG TCCTGAATRCA 3: 5'AGCTRGAATTCAGGACACA GTGTACCA 3' The Vitellogenin ERE probe. which encompasses the FRF of the Xenomer Vitullogenin 42 gene

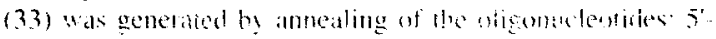

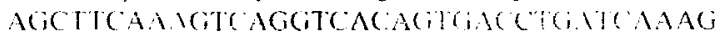

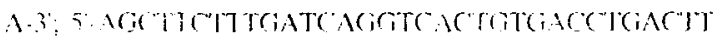

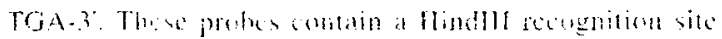

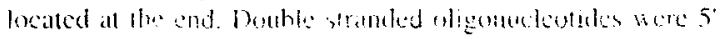

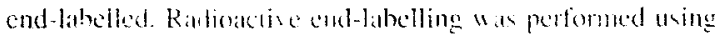

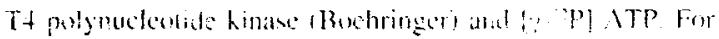

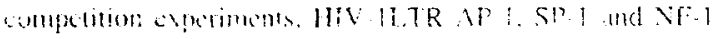

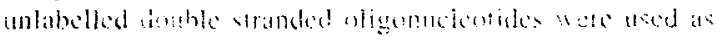

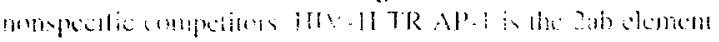

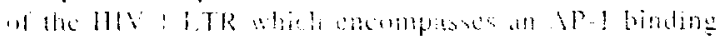

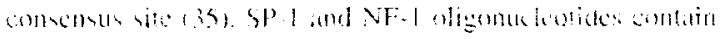

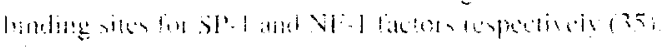

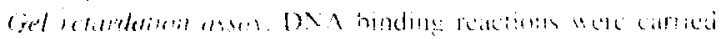

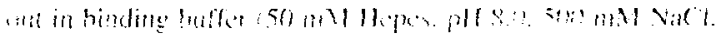

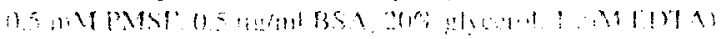

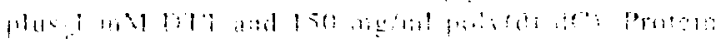

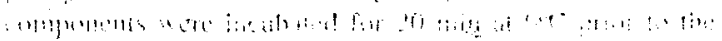

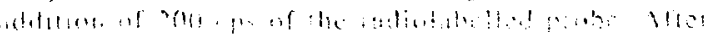

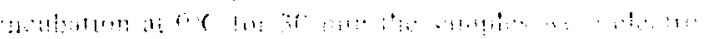

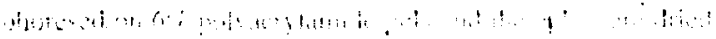

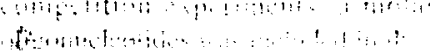

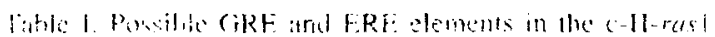
en:

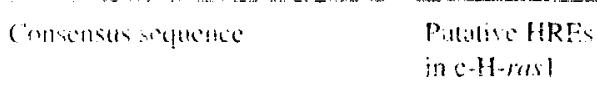

GRF:

(iRE:

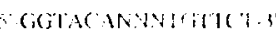

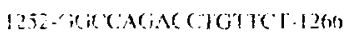

ERF::

ERE:

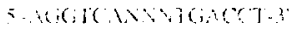

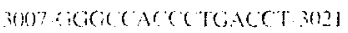

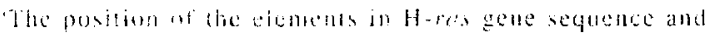

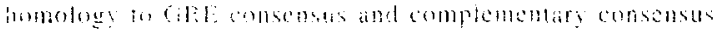
squences alle alot shownt

the addition of the radiolabelled prone for band shift experimencs polycional (rabbic) anti-human $\mathrm{GR}$ antihody (PA)-510. Affinity Binreagents) was included in the reacion mixture and incubated at $0 \mathrm{C}$ for $15 \mathrm{~min}$.

Compurer scamning. We used Cyborg/Pustell sequence analysis programs to search the nucleocide sequence of the human H-rasl gene (36). For identifying possible GREs. we scanned the human c-H-ras sequence for the highly conserved hexanucleotide 5'-TGTTCT-3' and the complementary 5'-ACAAACA-3' sequence. For EREs, the 5'TCACC ${ }^{-}-3$ and the complementary 5 -AGGICA-3' motifs were nsed.

\section{Results}

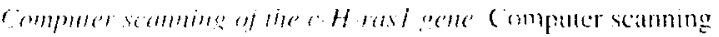

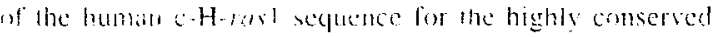
glesoorticoid response sequence reveated sereral possible

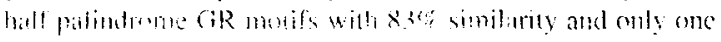
gerfecty matching the consered mexamulentide. The sequence of this motif and its position in the H-ras gene and

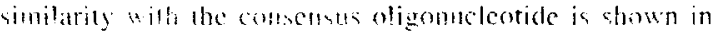

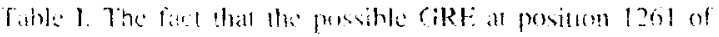

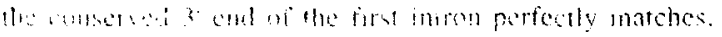

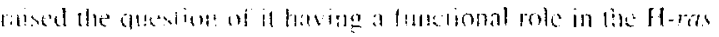

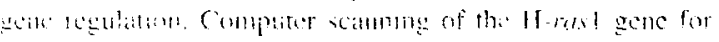
ERS

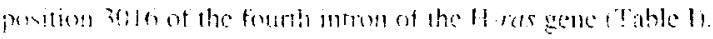

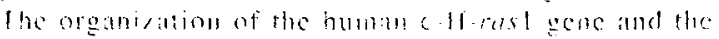

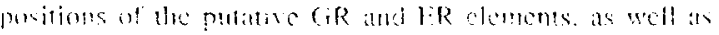

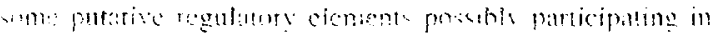

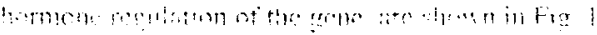

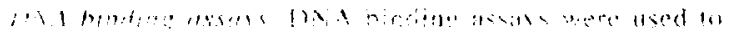

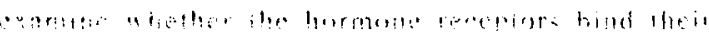

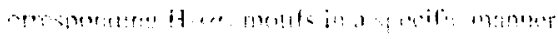

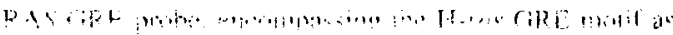

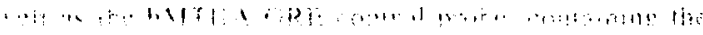

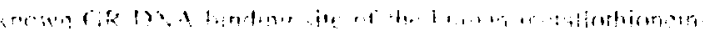

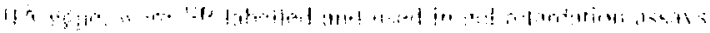




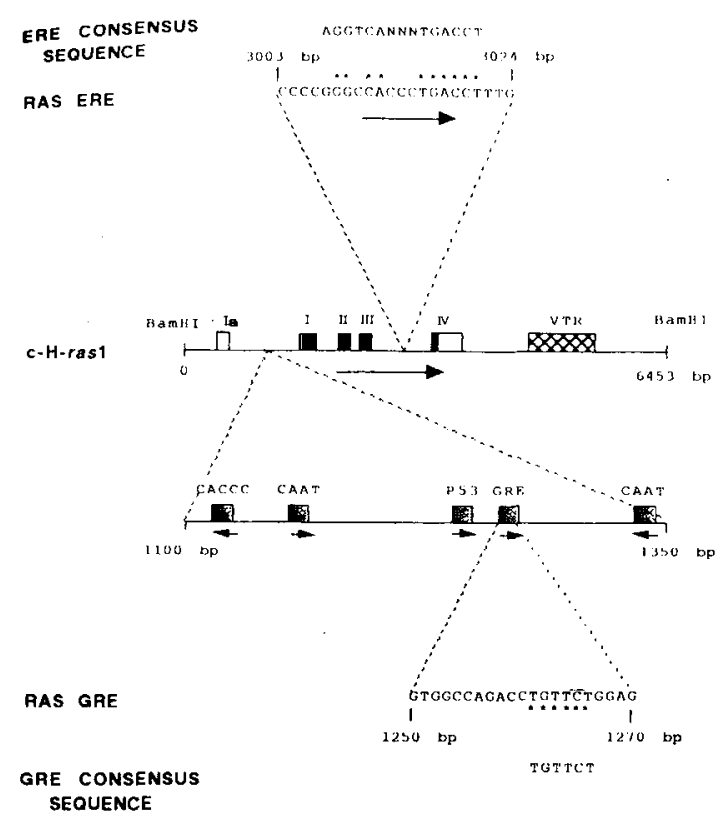

Figure 1. Organization of the human c-H-rasl gene-sequences and positions of the H-ras glucocorticoid responce element (GRE) and estrogen response element (ERE). Some possible regulatory elements in the vicinity of the $\mathrm{H}$-ras GRE are also shown. The coding sequences are represented by black boxes, the untranslated sequences by open boxes, the VTR by a crosshatched box and the regulatory elements by shadowed boxes. The direction of transcription is indicated by arrows. Asterisks indicate homology between hormone response elements and the corresponding consensus oligonucleotides.

HeLa and $\mathrm{LATK}^{-}$nuclear extacts were used as a source of GR. Fig. 2 shows the interaction of GR and H-ras GRE. The labelled hMTIIA GRE and RAS GRE probes were incubated with HeLa nuclear extract in the absence (lanes 1,7) or presence of unlabelled oligonucleotide competitors. The labelled probes were competed for protein binding with a molar excess of unlabelled oligonucleotides: (lanes 2,8), with each other (lanes 3,9) and with the unrelated SP-1 (lanes 4,10), NF-1 (lanes 5,11) and HIV-1LTR AP-1 (lanes 6,12). A common retarded band was seen in lanes 1 and 7 , indicating the presence of a GR-DNA complex. Binding of GR on RAS GRE probe was abolished in the presence of excess of GRE containing competitors, but was unaffected by the other competitors such as SP-1, NF-1 or HIV-1 LTR-AP-1. An equivalent picture resulted from the hMTIIA GRE probe. Fig. 2 showed a strong sequence specificity of a protein for the H-ras DNA target and suggested that this protein was the GR, as it was shown by the common band in lanes 1 and 7 and was displaced only by GRE-related competitors.

A further, more direct demonstration of the GR-H-ras GRE interaction is shown in Fig. 3. ${ }^{32} \mathrm{P}$-labelled RAS GRE probe was incubated with HeLa nuclear protein, in the absence (lane 3), or presence (lanes 4-6) of increasing amounts of polyclonal anti-human glucocorticoid receptor antibody. Control hMTIIA GRE probe was also incubated, in

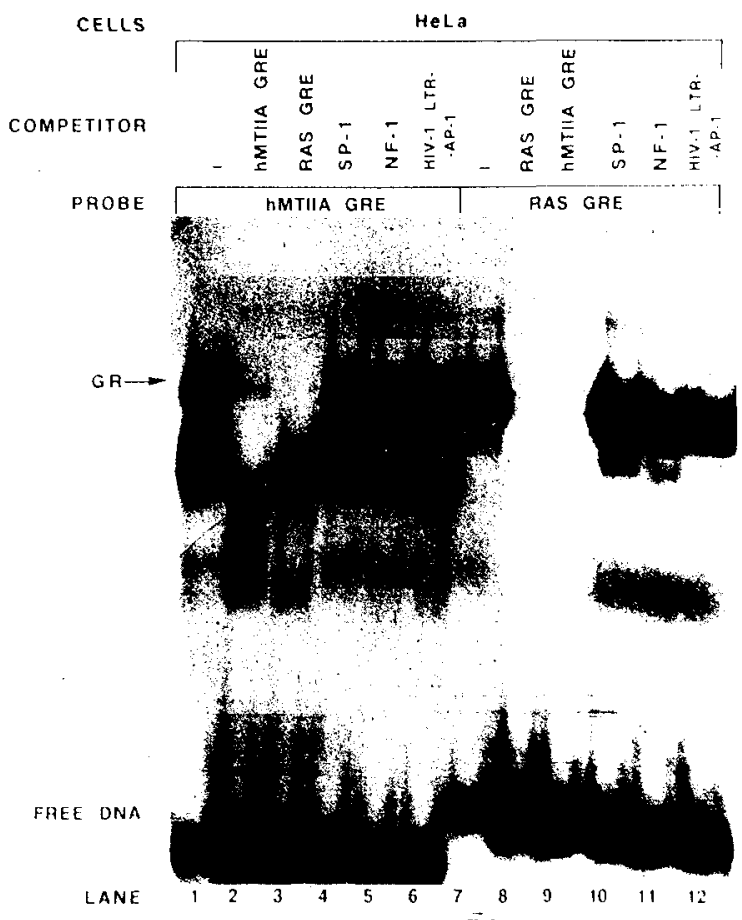

Figure 2. Sequenee specific binding of GR to the H-ras GRE. Binding reaction mixtures contained $15 \mu \mathrm{g}$ of HeLa total nuclear protein, 0.01 pmoles of $\gamma^{32}$ P-end labelled probes hMTIIA GRE (lanes 1-7) and RAS GRE (lanes 8-12) and a 150 fold molar excess over the labelled probe of the unlabelled competitor oligonucleotide (lanes 2-6 and 8-12). Protein-DNA complexes were separated by polyacrylamide gel electrophoresis and visualized by autoradiography. GR-RAS GRE complex is indicated by the arrow.

the absence (lane 1) or presence (lane 2) of polyclonal antihuman GR antibody. Inclusion of the antibody into the reaction mixture led to the disappearance of the specific retarded band, clearly indicating that this was due to GRDNA interaction.

The hMTIIA GRE and RAS GRE radiolabelled probes were incubated with increasing amounts of GR-containing HeLa (lanes 6-11) and LATK- (lanes 1-5) extracts (Fig. 4). A retarded band was seen and a stronger GR-DNA complex was observed, in both cell lines, with increasing amount of nuclear extract.

RAS ERE probe, encompassing the H-ras ERE sequence and Vitellogenin ERE probe, encompassing the estrogen response sequence from Xenopus Vitellogenin A2 gene were used for ER binding experiments. The labelled Vitellogenin ERE and RAS ERE probes were incubated with HeLa nuclear extract in the absence (lanes 1,5 ) or presence of an excess of unlabelled oligonucleotide competitors (Fig. 5). The labelled probes were competed for protein binding with related (lanes 2,6) and unrelated (lanes 3,4,7,8) unlabelled oligos. A common retarded band was seen in lanes 1 and 5 , indicating the presence of an ER-DNA complex. Binding of ER on the RAS ERE probe was abolished only in the presence of excess of ERE related competitors, indicating specific binding of estrogen receptor on the H-ras ERE. 


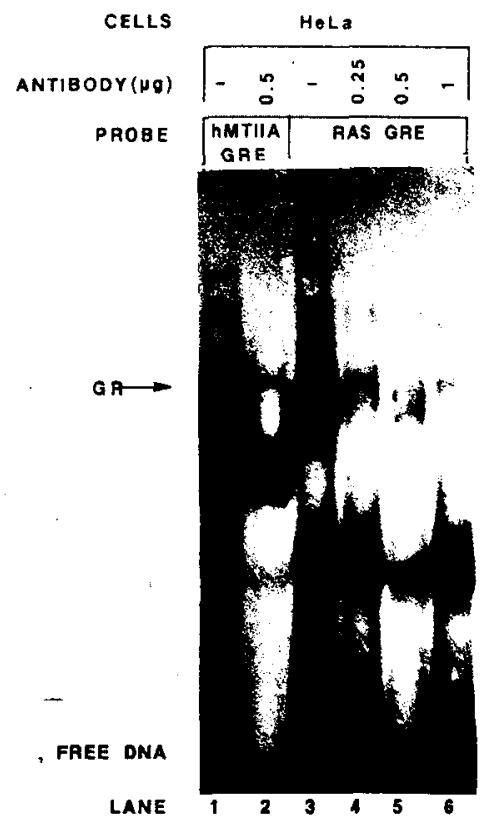

Figure 3. Identification of GR-H-ras GRE complexes by specific antibody. Binding reaction mixtures contained $13 \mu \mathrm{g}$ of HeLa total nuclear protein, 0.01 pmoles of ${ }^{32} \mathrm{P}$ labelled hMTIIA GRE and RAS GRE probes, polyclonal anti-human glucocorticoid receptor antibody in amounts indicated above each lane. Protein-DNA complexes were separated as in Fig. 2.

\section{Discussion}

The steroid hormone receptors are one of the most extensively studied group of the known regulatory factors, however, little is still known about hormonal regulation of cellular oncogenes $(32,37,38)$. Using gel retardation assays we observed specific binding of hormone receptors in the $\mathrm{H}$ ras gene, at positions which were-previously predicted through computer scanning analysis. We showed that glucocorticoid receptor binds a consensus motif at position 1261 of the conserved $3{ }^{\prime}$ end of the first intron of the H-ras and that estrogen receptor binds a sequence at position 3007 , at the fourth intron of the gene. These results provide data for hormone regulation of the human $\mathrm{H}-$ rasl oncogene. Furthermore, potentially active HREs are found in sequences of the H-ras intron, suggesting a regulatory role for introns in the $\mathrm{H}$-ras gene expression. Moreover, the end of the first intron is evolutionarily well conserved (33), suggesting a functional role for the H-ras GRE in human and other organisms as well. The existence of other possible regulatory elements in the vicinity of the H-ras GRE as shown in Fig. 1 (39-41), also implies a functional role for the H-ras GRE.

Previous data for regulation of the murine $\mathrm{H}$-ras gene by glucocorticoids has been reported (42). The cooperation between glucocorticoid hormones and the T24 H-ras

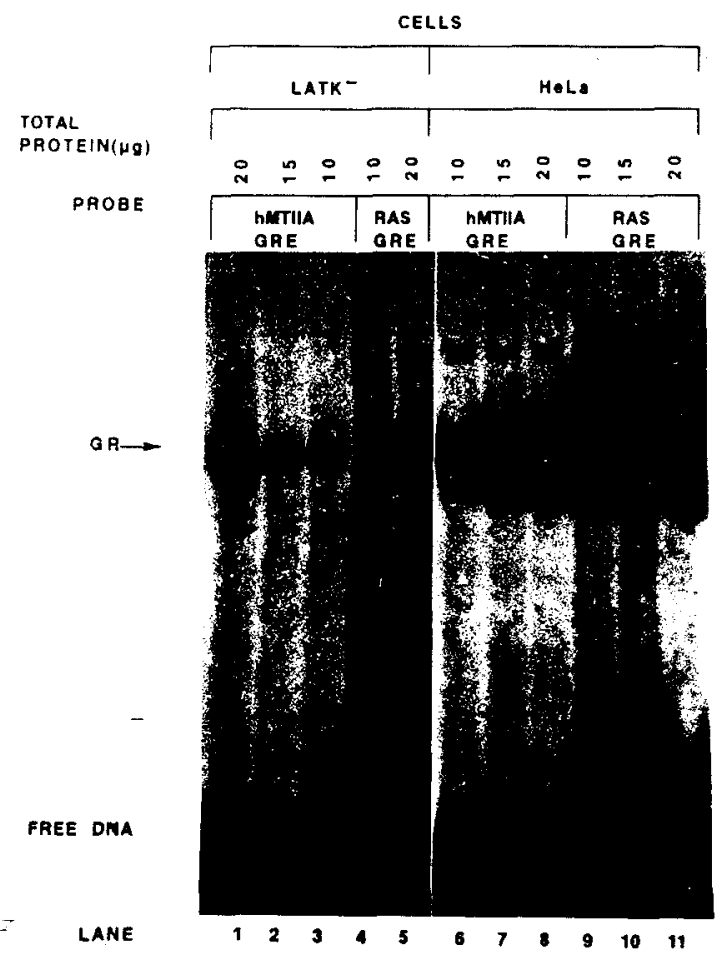

Figure 4, GR binding to GRE derived from two different cell lines. Binding reaction mixtures contained 0.01 pmoles of hMTIIA GRE (lanes 1-3 and 6-8) or RAS GRE (lanes 4,5 and 9-11) radiolabelled probe and 10,15, or $20 \mu \mathrm{g}$ of nuclear protein, as indicated above the lanes. LATK- (lanes 1-5) or HeLa (lanes 6-11) nuclear extracts were used. Protein-DNA complexes were separated as in Fig. 2.

oncogene in cell transformation (43) suggests the involvement of the $\mathrm{H}$-ras gene in hormonal promotion of breast tumors through abnormal hormonal regulation. In addition, development of breast carcinomas in rats has been shown to be initiated by mutations in the H-ras and K-ras genes and to depend on promotion by estrogens (44). The latency of ras oncogenes to induce cell transformation in the absence of hormonal stimulation (44) might be due to the inability of ras oncogenes to induce proliferation of the mammary precursor cells. Our experimental results suggest a more direct implication of H-ras in hormonal tumor promotion by proposing hormonal regulation of the $\mathrm{H}$-ras gene (normal or mutated), also providing an explanation for the specificity of tumor development in systems involving ras genes and sexual development.

Using ras $\mathrm{p} 21$ as a possible marker for the disease may be of prognostic significance. Depending on the way the H-ras gene is regulated by hormones, an explanation of indications correlating the levels of hormone receptors and prognosis of the disease may also be provided (45-47).

In conclusion, more data on the hormone regulation of the $\mathrm{H}-$ ras gene through specific receptor binding could be provided by combining in vitro $\mathrm{CAT}$ assay experiments and 

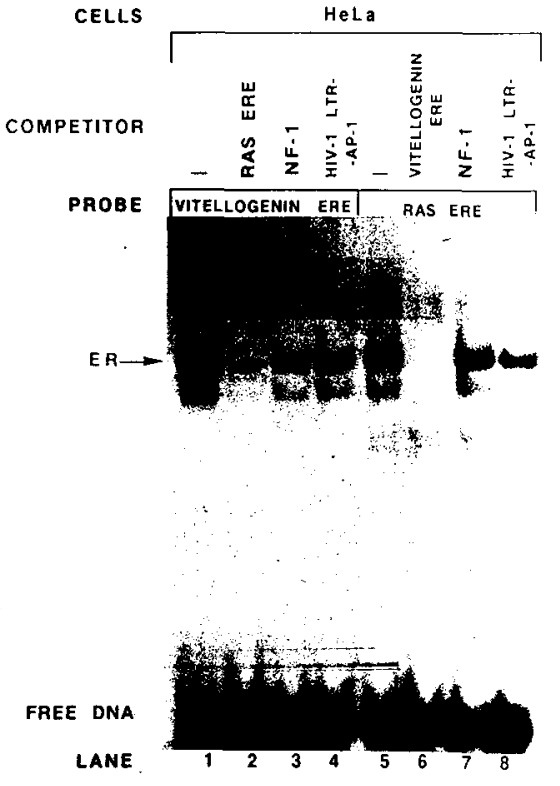

Figure 5. Binding of the ER to H-ras ERE. Binding reaction mixtures contained 0.01 pmoles of Vitellogenin ERE (lanes 1-4) or RAS ERE radiolabelled probe and $20 \mu \mathrm{g}$ of nuclear protein. Unlabelled RAS ERE (lane 2) and Vitellogenin ERE (lane 6) probes, as well as the unrelated probes NF1 (lanes 3,7) and HIV-1 LTR-AP-1 (lanes 4,8) were used in competition experiments. Protein-DNA complexes were separated as indicated in the Fig. 2 legend. ER-H-ras ERE complex is indicated by the arrow.

in vivo determination of the ras p21 levels in stable transfectants, when adding the corresponding hormone. Moreover, comparing the levels of the receptor binding in corresponding HREs in human tumors with the adjacent normal tissues, through gel retardation assays, may give additional evidence for the role of hormonal regulation of the $\mathrm{H}$-ras gene in human tumor progression.

\section{References}

1. Beato M: Gene regulation by steroid hormones. Cell 56: $335-$ $344,1989$.

2. Heck S, Kullmann M, Gast A, Ponta H, Rahmsdorf HJ, Herrlich P and Cato ACB: A distinct modulating domain in glucocorticoid receptor monomers in the repression of activity of the transcription factor AP-1. EMBO J 13: 4087-4095, 1994.

3. Ponta H, Cato ACB and Herrlich P: Interference of pathway specific transcription factors. Biochim Biophys Acta 1129: 255$261,1992$.

4. Klock G, Strahle U and Schultz G: Oestrogen and glucocorticoid responsive elements are closely related but distinct. Nature 329: 734-736, 1987

5. Klein-Hitpass L, Ryffel GU, Heitlinger E and Cato ACB: A13 bp palindrome is a functional estrogen responsive element and interacts specifically with estrogen receptor. Nucl Acids Res 16: 647-663, 1988

6. Jantzen HM, Strahle U, Gloss B, Stewart F, Schmid W, Boshart M, Miksicek R and Schutz G: Cooperativity of glucocorticoid response elements located far upstream of the tyrosine aminotransferase gene. Cell 49: 29-38, 1987

7. Ponglikitmongol $\mathrm{M}$. White JH and Chambon P: Synergistic activation of transcription by the human estrogen receptor bound to tandem responsive elements. EMBO J 9: 2221-2231. 1990 .
8. Cordingley MG, Riegel AT and Hager GL: Steroid-dependent interaction of transcription factors with the inducible promoter of mouse mammary tumor virus in vivo. Cell 48: 261-270, 1987.

9. Schule R, Muller M, Kaltschmidt C and Renkawitz R: Many transcription factors interact synergistically with steroid receptors. Science 242: 1418-1420, 1988.

10. Bruggemeler U, Kalff M, Franke S, Scheidereit $C$ and Beato $M$ : Ubiquitous transcription factor OTF- 1 mediates induction of the MMTV promoter through synergistic interaction with hormone receptors. Cell 64: 565-572, 1991

11. Schedereit C, Geisse S, Westphal HM and Beato M: The glucocorticoid receptor binds to defined nucleotide sequences near the promoter of mouse mammary tumor virus. Nature 304 $749-752,1983$

12. Schedereit $C$ and Beato $M$ : Contacts between hormone receptor and DNA double helix within a glucocorticoid regulatory element of mouse mammary tumor virus. Proc Natl Acad Sci USA 81: 3029-3033, 1984.

13. Konig $\mathrm{H}$, Ponta $\mathrm{H}$, Rahmsdorf $\mathrm{H}$ and Herrlich P: Interference between pathway-specific transcription factors: glucocorticoids antagonize phorbol ester-induced AP-1 activity without altering AP-1 site occupation in vivo. EMBO J 11: 2241-2246, 1992.

14. Yang-Yen HF, Chambard JC, Sun Y, Smeal T, Schmidt T, Drouin $\mathrm{J}$ and Karin M: Transcriptional interference between cJun and the glucocorticoid receptor: mutual inhibition of DNA binding due to direct protein-protein interaction. Cell 62: 1205$1215,1990$.

15. Kato S, Tora L, Yamauchi J, Masushige S, Bellard M and Chambon P: A far upstream estrogen response element of the ovalbumin gene contains several half-palindromic 5'-TGACC-3' motifs acting synergistically. Cell 68: 731-742, 1992.

16. Naar A, Boutin J, Lipkin SM, Yu VC, Holloway JM, Glass CK and Rosenfeld MG: The orientation and spacing of core DNAbinding motifs dictate selective transcriptional responses to three nuclear receptors. Cell 65: 1267-1279, 1991.

17. Halachmi S, Marden E, Martin G, MacKay H, Abbondanza C and Brown M: Estrogen receptor-associated proteins: possible mediators of hormone induced transcription. Science 264: 1455$1458,1994$.

18. Karin M, Haslinger A, Holtgreve H, Richards RI, Krauter P, Westphal HM and Beato M: Characterization of DNA sequences through which cadmium and glucocorticoid hormones induce human metallothionein-IIA gene. Nature 308: 513-519, 1984.

19. Fan W, Trifiletti $R$, Cooper $T$ and Norris JS: Cloning of a $\mu$ class glutathione $S$-transferase gene and identification of the glucocorticoid regulatory domains in its 5 ' flanking sequence. Proc Natl Acad Sci USA 89: 6104-6108, 1992.

20. Renkawitz R, Schutz G, von der Ahe D and Beato $M$ : Sequences in the promoter region of the chicken lysozyme gene required for steroid regulation and receptor binding. Cell 37: 503-510, 1984.

21. Slater E, Rabenau O, Karin M, Baxter JD and Beato M: Glucocorticoid receptor binding and activation of a heterologous promoter by dexamethasone by the first intron of the human growth hormone gene. Mol Cell Biol 5: 2984-2992, 1985.

22. Payvar F, DeFranco D, Firestone GL, Edgar B, Wrange O, Okret S, Gustafsson JA and Yamamoto KR: Sequence-specific binding of glucocorticoid receptor to MTV DNA at sites within and upstream of the transcribed region. Cell 35: 381-392, 1983.

23. Spandidos DA, Zoumpourlis V, Kotsinas A, Tsiriyotis C and Sekeris CE: Response of human immunodeficiency virus long terminal repeat to growth factors and hormones. Anticancer Res 10: $1241-1246,1990$.

24. Buetti $E$ and Kuhnel B: Dinstinct sequence elements involved in the glucocorticoid regulation of the mouse mammary tumor virus promoter identified by linker scanning mutagenesis. J Mol Biol 190: 379-389, 1986.

25. Ghosh D: Glucocorticoid receptor-binding site in the human immunodeficiency virus long terminal repeat. J Virol 66: 586590,1992

26. Koffa M. Malamou-Mitsi V. Agnantis NJ and Spandidos DA: Mutational activation of K-ras oncogene in human breast tumors. Int J Oncol 4: 573-576. 1994.

27. Abdellatif M. MacLellan WR and Schneider MD: p21 Ras as a governor of global gene expression. J Biol Chem 269: 154231.5426 .1994$.

28. Spandidos DA and Wilkie NM: Malignant transformation of carly passage rodent cells by a single mutated human oncogene. Nature 310: 469-475, 1984 
29. Spandidos DA: The human T24 Ha-ras l oncogene: a study of the effects of overexpression of the mutated ras gene product in rodent cells. Anticancer Res 6: 259-262, 1986.

30. Spandidos DA, Frame $M$ and Wilkie N: Expression of the normal H-rasl gene can supress the transformed and tumorigenic phenotypes induced by mutant ras genes. Anticancer Res 10: 1543-1554, 1990.

31. Spandidos DA (ed.): The Superfamily of ras-Related Genes. Plenum Press, New York, ppl-338, 1991.

32. Sekeris CE: Hormonal steroids act as tumor promoters by modulating oncogene suppression. J Cancer Res Clin Oncol 117: 96-101, 1991

33. Hashimoto-Gotoh T, Takahashi $\mathrm{M}$, Kikuno $\mathrm{R}$, Ishihara $\mathrm{H}$ and Tezuka $\mathrm{K}$ : Unusual sequence conservation in intron- 1 of $\mathrm{c}-\mathrm{H}-$ ras oncogene and its effect on $\mathrm{p} 21$ protein synthesis. In: Current Perspectives on Molecular and Cellular Oncology vol.1, partA, D.A. Spandidos (ed.) pp211-230, 1992.

34. Sabbah M, Gouilleux F, Sola B, Redeuilh G and Boulieu E: Structural differences between the hormone and antihormone estrogen receptor complexes bound to the hormone response element. Proc Natl Acad Sci USA 88: 390-394, 1991.

35. Zoumpourlis V, Ergazaki $M$ and Spandidos DA: AP-1 recognizes sequence elements on HIV-1 LTR in human epithelial tumor cell lines. Oncol Rep 1: 397-401, 1994.

36. Capon DJ, Ellson YC, Levinson AD, Seeburg PH and Goeddel DV: Complete nucleotide sequences of the T24 human bladder carcinoma oncogene and its normal homologue. Nature 302: 33-37, 1983.

37. Weisz A, Bresciani F: Estrogen induces expression of c-fos and c-myc protooncogenes in rat uterus. Mol Endocrinol 2: 816-824, 1988.
38. Loose-Mitchel DS, Chiappetta C, Stancel GM: Estrogen regulation of $\mathrm{c}-\mathrm{f} o s$ messenger ribonucleic acid. Mol Endocrinol 2: $946-951,1988$.

39. Strahle U, Schmid W and Schutz G: Synergistic action of the glucocorticoid receptor with transcription factors. EMBO J 11 : 3389-3395, 1988.

40. Schule R, Muller M, Otsuka-Murakami $H$ and Renkawitz R: Cooperativity of the glucocorticoid receptor and the CACCCbox binding factor. Nature 332: 87-90, 1988.

41. Lucas PC and Granner DK: Hormone response domains. Annu Rev Biochem 61: 1131-1173, 1992.

42. Strawhecker JM, Bentz NA, Neades RY, Houser W and Pelling JC: Binding of the $97 \mathrm{kDa}$ glucocorticoid receptor to the $S^{\prime}$ upstream flanking region of the mouse c-Ha-ras oncogene. Oncogene 4: 1317-1322, 1989.

43. Marshall H, Martens I, Svensson C, Akusjärvi G and Linder S: Glucocorticoid hormones may partially substitute for adenovirus ElA in cooperation with ras. Exp Cell Res 194: 35$41,1991$.

44. Kumar R, Sukumar S and Barbacid M: Activation of ras oncogenes preceding the onset of neoplasia. Science 248: 1101$1104,1990$.

45. Kawasaki $\mathrm{E}$ and Erlich $\mathrm{H}$ : Polymerase chain reaction and analysis of cancer cell markers. J Natl Cancer Inst 82: 806-807, 1990.

46. Schwartz MR: Carcinoembryonic antigen and estrogen receptor: a prognostic duo in breast cancer? Cancer 74: 1519-1522, 1994.

47. Esteban JM, Felder B, Ahĩ C, Simpson JF, Battifora $H$ and Shively JE: Prognostic relevance of carcinoembryonic antigen and estrogen receptor status in breast cancer patients. Cancer 74: $1575-1583,1994$. 